\title{
Notas sobre o pensamento de Ignácio Rangel no centenário de seu nascimento
}

\author{
MÁRCIO HENRIQUE MONTEIRO DE CASTRO \\ RICARDO BIELSCHOWSKY \\ CÉSAR BENJAMIN*
}

Notes on the thought of Ignácio Rangel on the centenary of his birth.

This paper is a tribute to one of the greatest Brazilian intellectuals of the $\mathrm{XX}^{\text {th }}$ century, Ignácio Rangel, at the Centenary of his birth. The two analytical pillars of his thought are discussed, namely the thesis of the long term "basic duality" of the Brazilian economy and of the national political structure, and the idea that economic planning should always involve the identification and use of idle resources. It is argued that his ideas on history and his defense of planning integrate a wider development theory, which combines structural change (industrialization, agrarian modernization, the strengthening of the financial capital, etc.) and a macro-dynamic approach on idle capacity and economic cycles. By way if conclusion the ideas are evaluated from a XXIt century perspective.

Keywords: Ignácio Rangel; basic duality; economic cycles.

JEL Classification: 2B.

Há cem anos nasceu Ignácio Rangel e há vinte nos deixou, depois de uma vida excepcionalmente produtiva. Participou bem jovem da Revolução de 1930. Em seguida, integrou a Aliança Nacional Libertadora (ANL), logo considerada ilegal. Tornou-se autodidata na prisão, quando iniciou uma revisão crítica das principais teses defendidas pela esquerda. Manteve-se fiel à formação marxista, mas, ao longo do tempo, formulou uma construção analítica própria, uma criativa adaptação do materialismo histórico ao caso do Brasil. Afastou-se de todas as correntes de pensamento consolidadas, inclusive em seu próprio campo ideológico, o socialista,

\footnotetext{
* Respectivamente, Doutor em economia pela Unicamp, Professor da UFF. E-mail: mhmcrj@hotmail. com; Doutor em economia pela Universidade de Leicester, Inglaterra, Professor da UFRJ. E-mail: ricardo. bielschowsky@gmail.com; Doutor Honoris Causa pela Universidade Bicentenária de Aragua, Venezuela, Editor da Contraponto Editora. E-mail: cesarben@uol.com.br.
} 
e tornou-se o mais original pensador econômico brasileiro do século XX. Participou da assessoria econômica do segundo governo de Getulio Vargas e do Plano de Metas de Juscelino Kubitschek. Chefiou o Departamento Econômico do BNDE (hoje BNDES), entre muitas outras funções. Deixou uma obra instigante, ampla e complexa, que aqui só podemos tangenciar.

Trabalhou até o fim da vida. Seus últimos artigos - e conversas - trataram, entre outros temas, da desagregação da União Soviética, da crise brasileira, da natureza não inercial da nossa inflação e, para espanto de muitos, da proposta de privatizar serviços de utilidade pública. Aos oitenta anos, continuava a ser um pensador surpreendente.

Para refletir sobre a atualidade de sua obra destacaremos os dois pilares analíticos que sempre estiveram presentes nela: a tese da dualidade básica da economia brasileira e a proposta de que o planejamento econômico deve partir, em cada momento, da identificação dos recursos ociosos. Como veremos, ambas condicionam as posições mais polêmicas que assumiu.

Sua defesa do planejamento integra uma teoria mais ampla do desenvolvimento, que combina transformações estruturais (industrialização, modernização agrária, alterações na inserção externa, fortalecimento do capital financeiro) com uma abordagem macrodinâmica vinculada à dialética da capacidade ociosa e dos ciclos econômicos. Acima de tudo estava a sua crença na progressiva interiorização do impulso dinâmico da economia brasileira. Para ele, Estado e planejamento eram facilitadores e amplificadores de um processo histórico mais geral, no qual os movimentos endógenos da nossa sociedade, gradativamente, tornavam-se cada vez mais importantes.

\section{A DUPLA DETERMINAÇÃO}

A tese da dualidade básica é o núcleo - e a parte menos compreendida — de sua obra. Apresentada em 1957, foi retomada em 1962, 1978 e 1981루, incorporando aspectos novos, às vezes não coincidentes. Rangel reafirmou diversas vezes a centralidade dessa hipótese em seu pensamento, e justamente por isso dedicou-se a aperfeiçoá-la ao longo do tempo ${ }^{2}$. Tentemos resumi-la.

Ele defendia que a dinâmica histórica brasileira se distingue dos casos clássicos porque aqui os processos sociais, econômicos e políticos não decorrem apenas da

\footnotetext{
1 "Dualidade básica da economia brasileira" (1957), "A dinâmica da dualidade brasileira" (1962), "Dualidade e 'escravismo colonial”" (1978) e "A história da dualidade brasileira" (1981). Todos os textos estão publicados nos dois volumes das Obras reunidas de Ignácio Rangel, organizados por César Benjamin (2005).

${ }^{2}$ Em "Dualidade e 'escravismo colonial'”, Rangel escreveu: "A ideia central da dualidade [...] parece-me muito fecunda para explicar a evolução [...] do Brasil. [...] Toda a minha contribuição ao esclarecimento da problemática brasileira pode ser definida como aplicação do marxismo ao entendimento da economia e da sociedade brasileiras [...]. E a teoria da dualidade foi, precisamente, a chave para isso".
} 
interação entre desenvolvimento de forças produtivas e relações de produção internas, mas também da ligação que, desde a origem e tão profundamente, o país mantém com as economias centrais. Essas relações externas têm sido determinantes no desenvolvimento das nossas forças produtivas e, consequentemente, também das nossas relações de produção.

Essa dupla determinação, interna e externa, produz uma dualidade estrutural na economia e na sociedade brasileiras. Desenvolvendo-se como uma economia complementar ou periférica, o Brasil deve ajustar-se a uma economia externa diferente da sua. Por isso, nossa história transitou por uma sequência de pares de modos de produção simultâneos e articulados, as dualidades, que se estendem no tempo e demarcam períodos: "O princípio da dualidade é a combinação de relações de produção heterogêneas para compor um só e mesmo modo de produção complexo ou dual" 3 .

O raciocínio de Rangel preserva as categorias centrais do materialismo histórico e o sentido geral da história, tal como se depreende da obra de Marx, mas destaca a especificidade brasileira: "Respondendo, como qualquer outra formação, ao crescimento de suas próprias forças produtivas, muda o modo de produção, e o faz no mesmo sentido geral no qual muda a sociedade humana, passando a um modo de produção superior" 4 "Mas tem um modo peculiar de mudar, isto é, o faz em obediência a certas 'leis' específicas - as leis da dualidade brasileira"'.

É imenso o potencial heurístico dessa tese para a interpretação da nossa história. Ela apresenta uma argumentação singular sobre como os modos de produção se sucederam aqui. Do início do século XIX até a década de 1970 a história brasileira teria percorrido três dualidades, cada uma delas composta por dois polos, chamados interno e externo. Cada polo, por sua vez, apresenta dois lados, que Rangel chama, também, de interno e externo. O decurso da nossa história se dá, portanto, por meio do movimento articulado de "quatro grupos elementares de relações de produção, ordenados dois a dois" ${ }^{6}$.

A primeira dualidade - com o escravismo e o feudalismo no polo interno da economia (a fazenda) e o capitalismo mercantil no lado interno do polo externo — teria começado no primeiro quartel do século XIX, quando a crise da colonização resultou na Abertura dos Portos (1808) e na Independência (1822). Essa crise teve a função histórica de libertar o sistema econômico brasileiro da intermediação

\footnotetext{
3 “Dualidade e 'escravismo colonial'”, Obras reunidas, v. II, p. 634.

${ }^{4}$ Para Rangel, haveria uma linha de desenvolvimento que conteria cinco modos de produção fundamentais: comunidade primitiva, escravismo, feudalismo, capitalismo e socialismo. Mas ele compreendia que esse eixo comportava variações. O modo de produção asiático e a dualidade são exemplos de variantes, mas para estudarmos os inúmeros modos concretos de produção "as categorias fundamentais do materialismo histórico [...] devem ser, obrigatoriamente, nosso ponto de partida”. Ver "Dualidade e 'escravismo colonial'”.

5 “A história da dualidade brasileira", Obras reunidas, v. II, p. 662.

6 "Dualidade e 'escravismo colonial”", Obras reunidas, v. II, p. 634.
} 
parasitária da Metrópole portuguesa, desobstruindo o caminho para a atuação do capital mercantil internacional e para a formação de capital na antiga Colônia, processos que impulsionaram o desenvolvimento das forças produtivas no século XIX.

A segunda dualidade se inicia com a abolição do comércio de escravos na segunda metade do século XIX, que teria determinado uma crise nas relações de produção da fazenda escravista e forçado a transição dela para o "latifúndio feudal", sob pressão do desenvolvimento das forças produtivas requisitadas pelo ciclo expansivo do café. O capitalismo mercantil aparece como formação dominante no polo externo da dualidade, lançando as bases do futuro capital industrial, enquanto no polo interno surge o latifúndio "internamente feudal" - mas voltado para a produção de bens exportáveis - formado a partir da desagregação da fazenda escravista.

O começo da terceira dualidade coincide com a crise nas relações externas, causada pelo colapso de 1929 e a subsequente depressão da década de 1930 . Nesse período, o desenvolvimento das forças produtivas ficou obstruído pela retração do mercado internacional, o que determinou novas e profundas transformações na economia brasileira. A crise levou ao declínio do capital mercantil, substituído, no polo externo, por uma nova formação, o capitalismo industrial. A partir daí, a indústria se desenvolveu ao lado do "latifúndio feudal" preexistente, que não chegou a ser profundamente afetado pela crise externa e se tornou dominante no polo interno. As funções básicas do capital mercantil, no entanto, foram sendo gradualmente assumidas pelo Estado, com a transição do liberalismo econômico ao controle estatal sobre o comércio exterior. Essa terceira dualidade, ainda segundo Rangel, se esgotou na década de 1970.

\section{A DUALIDADE NA POLÍTICA E A DESCOBERTA DE KONDRATIEFF}

Antes de tratarmos da quarta dualidade - que, em tese, corresponderia ao período atual — duas digressões são necessárias.

A interpretação rangeliana inclui a sucessão de dualidades também no domínio da política. À evolução nos modos de produção duais na economia correspondem alterações nas estruturas políticas - também duais -, como resultado do enfraquecimento de uma das duas classes dirigentes e do simultâneo surgimento de uma nova classe, que se torna proeminente na fase de transição para o novo modo de produção. A formação de novas dualidades ocorre, pois, com modificações político-institucionais.

A contrapartida política da primeira dualidade foi a formação de uma coligação de poder entre o latifúndio escravista, sócio maior, e o capital mercantil, sócio menor. Na segunda dualidade, este último se torna o sócio maior, enquanto o novo "latifúndio feudal" assume o lugar de sócio menor. A crise da década de 1930 corrói o poder do capital mercantil e concede hegemonia ao latifúndio feudal, sócio 
maior da nova coligação de poder, que teve no capital industrial o seu novo sócio menor.

Depois de formular sua tese e, com base nela, apresentar essa reinterpretação da história brasileira, Rangel percebeu que a sucessão de dualidades coincidia com as inflexões de ciclos da economia internacional que haviam sido propostos na década de 1920 pelo economista russo Nikolai Kondratieff. Era uma constatação que se encaixava perfeitamente em sua própria formulação original, complementando-a.

Kondratieff havia sugerido que, além de ciclos curtos e médios, então já conhecidos, a economia internacional estava sujeita também a ciclos longos, com 48 a 60 anos de duração, divididos em uma fase ascendente e uma descendente. Partindo de curvas empíricas, construídas com dados de Alemanha, França, Inglaterra e Estados Unidos, ele elaborou curvas teóricas que mostravam tendências seculares ${ }^{7}$.

$\mathrm{O}$ economista russo considerou ter encontrado dois ciclos longos entre 1780 e 1920, anunciando que, quando escrevia, iniciava-se a fase descendente do terceiro ciclo. Seu trabalho foi duramente criticado na antiga União Soviética, pois a existência desses ciclos, com suas inflexões sucessivas, enfraquecia a ideia de que o capitalismo rumava para uma grande crise que seria a antessala do socialismo. Embora silenciado em seu país, suas ideias foram revitalizadas com a publicação de Business Cycles, de J. A. Schumpeter. Essa obra monumental admite que a dinâmica do sistema capitalista combina ciclos curtos, médios e longos, e dá a cada um o nome do economista que melhor os descreveu: respectivamente, Kitchin, Juglar e Kondratieff. ${ }^{8}$

Notando a coincidência entre a sua periodização, elaborada para o Brasil, e a do economista russo, elaborada para o sistema internacional como um todo e tendo como referência as economias centrais, Rangel propôs que cada dualidade começa nas fases descendentes dos ciclos de Kondratieff, como resposta brasileira a esses grandes movimentos da economia mundial. Eles determinam crises nas relações de produção no Brasil — ora em suas relações internas, ora em suas relações externas - , afetando decisivamente, mas não mecanicamente, o desenvolvimento das forças produtivas locais. Na dialética rangeliana, o desenvolvimento das forças produtivas em escala mundial empurra o movimento das dualidades brasileiras, mas a maneira como essas dualidades se desenvolvem mostra que nossa sociedade reage ativamente, com dinâmica própria, aos eventos mundiais.

\section{A ANTEVISÃO DA QUARTA DUALIDADE}

A década de 1970 coincidia com a fase descendente do quarto ciclo de Kondratieff. Nela, segundo Rangel, estaríamos ingressando no quarto modo de produ-

\footnotetext{
${ }^{7}$ Cf. Kondratieff (1984).

${ }^{8}$ Cf. Shumpeter (1968).
} 
ção dual, ou quarta dualidade, que, curiosamente, seria caracterizada pelo semicapitalismo no polo interno (agrícola) e o capitalismo industrial e financeiro no polo externo. A ideia, que já aparecera de passagem em um instigante artigo de 1962, reaparece com força em $1981^{9}$, quando a quarta dualidade começa a ser pensada em termos de história corrente.

O motivo profundo da crise brasileira de então era o esgotamento das virtudes criadas pela terceira dualidade. Combinavam-se dois movimentos cíclicos: o juglariano brasileiro, fruto da industrialização por substituição de importações, e o Kondratieff engendrado pelo movimento das economias centrais. Mas Rangel permanecia otimista: a conjuntura internacional conduziria a alterações no centro dinâmico ou, pelo menos, a um enfraquecimento da "hegemonia mundial do imperialismo [...], deixando ao Terceiro Mundo a possibilidade de escolher seus próprios caminhos [...] a começar pelo mundo socialista" ${ }^{10}$.

Em textos escritos em 1981 e em $1990^{11}$, a terceira (1922-1973) e a quarta (1973-...) dualidades coincidiam nos respectivos lados internos (capitalismo industrial) e externos (capitalismo financeiro, com organização nacional e estatal das finanças e do comércio exterior) do polo externo. As mudanças ocorreriam no polo interno, tanto no lado interno (feudalismo na terceira dualidade, semissalariato/salariato na quarta dualidade) quanto no lado externo (latifúndio e capitalismo mercantil na terceira dualidade, semicapitalismo rural e empresa rural na quarta dualidade).

Os textos não explicam por que Rangel usou semicapitalismo para definir os elementos do polo interno. Tudo leva crer que ele estava destacando a situação de trabalho temporário dos chamados boias-frias, que não seria um elemento característico de nenhum modo de produção. Seja como for, a quarta dualidade, que resultaria da transformação do polo interno da terceira dualidade, deveria ter capitalismo industrial e trabalho assalariado nesse polo: "No caso da quarta dualidade, em via de implantação, o latifúndio, classe hegemônica da anterior dualidade, está sendo substituído por uma dissidência sua: a empresa capitalista, onde o servo da gleba será substituído pelo trabalhador assalariado e onde o trabalho manual começa a ser ativamente substituído pela máquina e pela química" ${ }^{12}$.

A formulação aponta para uma aproximação entre os elementos díspares que antes caracterizavam as dualidades — os aspectos feudais e os mercantis. Isso significava que a própria sucessão de dualidades estava chegando ao fim ${ }^{13}$.

\footnotetext{
9 “A quarta dualidade" (1980), Obras reunidas, v. II, p. 645, e "A história da dualidade brasileira" (1981), Obras reunidas, v. II, p. 655, onde encontramos uma apresentação mais detalhada.

10 “A quarta dualidade” (1980), Obras reunidas, v. II, p. 646.

11 “A história da dualidade brasileira” (1981) e "A quarta dualidade” (1990).

12 "A quarta dualidade" (1990).

13 "A história da dualidade brasileira" (1981), Obras reunidas, v. II, p. 685.
} 


\section{AS GRANDES PROPOSTAS: A QUESTÃO AGRÁRIA}

Para Rangel, desenvolvimento requer planejamento, e a base para um bom planejamento é a mobilização dos recursos ociosos existentes no sistema produtivo. Sempre afirmando a existência de ondas cíclicas recorrentes de expansão e retração no médio e no longo prazos (ciclos de Juglar e de Kondratieff), ele defendia que nas fases ascendentes dos ciclos médios o planejamento deve mobilizar recursos ociosos nos elos fortes da economia para construir as novas frentes de expansão nos elos fracos. Em um contexto de crise que ele associava à fase descendente do quarto ciclo de Kondratieff e ao amadurecimento da nova dualidade brasileira, apresentou propostas que visavam preparar um novo ciclo expansivo de longo prazo.

Tratava-se, basicamente, de quatro grandes medidas: (a) uma nova organização do agro brasileiro; (b) a privatização dos serviços de utilidade pública; (c) o desenvolvimento do capital financeiro nacional e estatal; (d) a organização estatal do comércio exterior. Essas transformações permitiriam que nossa economia estabelecesse novas relações com as economias centrais, tornando-se capaz de crescer na contramão delas, como ocorrera na fase descendente do terceiro Kondratieff. Destacaremos as duas primeiras, nas quais fica patente a originalidade do pensamento de Rangel.

Durante a terceira dualidade, nosso desenvolvimento se caracterizara pelo avanço da industrialização sem prévia reforma agrária, de modo que os ciclos de substituição de importações atendiam a um mercado que já existia. Essa trajetória também resultou em uma estrutura agrária heterogênea, com a presença de latifúndios que mantinham formas feudais de organização da produção, de unidades familiares pré-capitalistas e de unidades capitalistas propriamente ditas.

A modernização elevava a produtividade da agricultura e implicava a ruptura do antigo "complexo rural", que tendia à autossuficiência. Além de produzir bens agrícolas propriamente ditos, a agricultura feudal e a unidade familiar produziam uma cesta de bens que deveria estar a cargo dos setores secundário e terciário, sendo adquirida no mercado. A modernização agrícola, com a intensificação da divisão social do trabalho, implicava reduzir o trabalho da família camponesa à agricultura, concentrando a jornada familiar, cada vez mais, em atividades voltadas para o mercado.

Do ponto de vista econômico, era um processo progressista, pois aumentava a potência das forças produtivas e possibilitava introduzir relações de produção mais avançadas. Mas criava problemas sociais: ao destruir o complexo rural, a economia gerava um excedente estrutural de mão de obra que não podia ser absorvido.

$\mathrm{Na}$ época em que a nossa industrialização se apoiava em um setor de bens de produção arcaico, que precisava de muita mão de obra, a reforma agrária não era necessária, pois aquele setor absorvia a força de trabalho expelida do campo com a desestruturação do complexo rural. A crise agrária apresentava, então, marcante componente cíclico, só aparecendo quando caía a taxa de investimento na indústria. 
Contudo, a modernização simultânea do campo e da indústria pesada agravava e tornava permanente a questão agrária.

A solução não era um retorno à economia camponesa. Era preciso, de um lado, facilitar o desenvolvimento do capitalismo no campo, incentivando o uso capitalista do solo, sem sustentar o preço da terra e os velhos esquemas de comercialização, que ajudavam o latifúndio atrasado. De outro lado, tratava-se de viabilizar a reestruturação do complexo rural sob outra forma, com a generalização gradativa da produção mercantil e da relação de salariato, sem prejuízo de que as famílias pudessem realizar uma produção complementar, voltada para o consumo próprio. Era uma solução temporária, tanto do ponto de vista do campo como da cidade. Buscava garantir as vantagens oriundas da introdução do capitalismo no campo e, ao mesmo tempo, resolver os problemas causados pela desestruturação da agricultura tradicional.

Rangel destaca duas dimensões da questão agrária: a dimensão financeira, relacionada com o uso da terra como ativo para valorização ou reserva de valor, e a percepção de que a crise agrária se intensifica e se torna crônica na medida em que o processo de industrialização avança para os setores produtores de bens de capital. Em seguida, ele formula propostas que se afastavam daquelas mais comumente defendidas pela esquerda. Rangel pensava em agrovilas (pequenos lotes "rururbanos") que compatibilizariam a sazonalidade da utilização da mão de obra pela grande produção capitalista agrícola com a permanência de um novo complexo rural, moderando os efeitos urbanos da modernização agrícola.

A luta atual pela terra, que gerou um dos movimentos sociais mais importantes da história brasileira, exemplifica a atualidade de suas propostas: a questão agrária extrapolou o mundo rural e hoje assume uma explosiva face urbana, que impõe novas soluções, tendo em vista as dificuldades de implementação da reforma agrária no Brasil. A fecundidade dessas ideias pode ser vista no número de autores e de obras que elas influenciaram, direta ou indiretamente. Elas ecoam em todo o debate, relativamente recente, sobre a urbanização do campo brasileiro e a modernização conservadora da nossa agricultura.

\section{AS GRANDES PROPOSTAS: A PRIVATIZAÇÃO DOS SERVIÇOS DE UTILIDADE PÚBLICA}

A segunda grande medida relacionada à quarta dualidade — a privatização dos serviços de utilidade pública -, foi uma das propostas mais polêmicas e mais incompreendidas feitas por Rangel. Nossa industrialização, como se sabe, seguiu um caminho específico, com a implantação, primeiro, de setores leves, sucedidos gradativamente pelos mais pesados. No final da década de 1970 restava modernizar, principalmente, os serviços de utilidade pública, ou setores de infraestrutura. Eles tinham sido organizados de diferentes maneiras ao longo do tempo: operados por concessionárias privadas estrangeiras no início, depois como serviços públicos sujeito à administração direta e, por fim, entregues a concessionárias públicas. 
Estava na hora, segundo Rangel, de organizá-los na forma de concessões a empresas privadas, para que os investimentos pudessem ser financiados pelo mercado de capitais.

A proposta aparece em seus textos na segunda metade da década de 1970, mas ele mesmo afirmou que tomara consciência do problema muito tempo antes, no início da década de 1950, quando trabalhava no projeto de criação da Eletrobras. Ali se deu conta de que a empresa que seria criada teria dificuldades para levantar recursos no mercado de capitais, pois era, ao mesmo tempo, empresa pública e concessionária de serviço público.

Rangel percebeu que, do ponto de vista macroeconômico, realizar uma concessão de serviço público a uma empresa pública impediria o adequado financiamento da expansão da infraestrutura com recursos privados. Mantendo-se o setor sob controle direto do Estado, os investimentos dependeriam de recursos fiscais. Como a infraestrutura seria o principal ponto de estrangulamento da economia - e, portanto, a grande frente de oportunidade de investimentos - esse tipo de financiamento implicaria tributar grande parte da poupança nacional, ou mesmo quase toda ela (mobilizar recursos para a infraestrutura por meio da expansão da dívida pública seria, tão somente, uma antecipação do uso dos recursos fiscais).

Ora, a garantia para que o setor privado financiasse o setor estatal - fosse diretamente, via mercado de capitais, fosse indiretamente, via títulos do governo - eram, justamente, os tributos futuros. No contexto acima descrito, em que a tributação tenderia a "engolir” o setor privado, formava-se um círculo vicioso que, segundo Rangel, estava na raiz da elevação da taxa de juros.

O setor privado detinha os recursos para o investimento (a capacidade ociosa, a poupança potencial), enquanto o setor público detinha as oportunidades de investimento, pois era dono do setor estrangulado, as estatais concessionárias de serviço público. O problema era estabelecer a necessária ligação entre as duas pontas, levando o setor superinvestido a financiar o setor subinvestido.

Como vimos, a via financeira, que estava sendo praticada, era uma variante disfarçada da via fiscal, pois se baseava no comprometimento de recursos fiscais. A segunda via, menos traumática e mais desejável, seria a do mercado de capitais, mas ela dependia do tipo de garantia que se poderia oferecer ao credor. Debruçado sobre essa problemática, Rangel desenvolveu sua ideia da privatização, não sob a ótica de uma simples transferência de ativos, mas como privatização das oportunidades de investimento. Ele sabia, no entanto, que transferir para a acumulação privada setores que estavam sob controle direto do Estado exigiria mudanças institucionais profundas.

Capitais privados poderiam financiar empreendimentos privados em infraestrutura, recebendo garantias reais na forma de hipoteca de bens imóveis. Tratava-se de uma inovação fundamental, pois no caso das estatais só havia a garantia fidejussória do aval lastreado em recursos fiscais futuros. A desconfiança em relação a esse tipo de aval em épocas de crise financeira do Estado - como era o caso no final da década de 1970 e na década de 1980 — impediria a atração dos recursos privados. 
Contudo, para que essa troca de posições funcionasse seria necessário resolver uma questão. Por razões técnicas, os serviços de utilidade pública são concessões do Estado. Isso quer dizer que seus ativos devem existir na sua forma natural e indivisível, ou seja, eles só podem ser dados em garantia a um ente que os receba globalmente. Esse ente tem de ser, necessariamente, o próprio Estado.

Então, como se poderia ofertar a garantia real necessária para viabilizar o financiamento privado a investimentos privados em infraestrutura? Rangel imaginou uma solução simples: sim, somente o Estado pode tomar em garantia os ativos técnicos das concessionárias, mas ele pode dar aval aos títulos de captação lançados por elas. Esse aval estaria lastreado na hipoteca dos ativos reais da concessionária ao Estado. Assim se constituiria uma garantia real para os títulos que financiariam a expansão da infraestrutura: títulos de hipoteca do empreendimento entregue em concessão.

Para muitos, isso representava uma rendição ao capitalismo e ao mercado. Para Rangel, estava na ordem natural do desenvolvimento brasileiro, pois essa alteração institucional solucionaria o impasse que começava a travar a nossa economia. Ele não aceitava uma dicotomia rígida entre privatização e estatização. $\mathrm{O}$ Estado recuaria no setor de infraestrutura, mas avançaria no planejamento do comércio exterior e na esfera financeira. Mesmo na infraestrutura, aliás, o Estado estaria mais forte e mais presente, como poder concedente e instância de planejamento. O aval estatal, baseado na hipoteca dos bens das concessionárias, seria a base de um ciclo de acumulação.

Sempre fiel à ideia de que o motor estrutural do nosso desenvolvimento é a dialética da capacidade ociosa, ele propôs mudanças institucionais que buscavam equacionar, simultaneamente, dois problemas: superar o estrangulamento do setor atrasado e ocupar a capacidade ociosa. Daí sua opção por uma solução privatizante, feita com capitais acumulados no espaço da economia brasileira, incluindo aí as empresas multinacionais. Não cabia insistir no financiamento público, pois já tínhamos uma crise fiscal instalada, tampouco usar crédito externo, pois ele impediria que dirigíssemos a demanda para as empresas instaladas no Brasil.

\section{A INFLAÇÃO BRASILEIRA}

Antes de caminharmos para a conclusão, com um balanço das contribuições de Rangel do ponto de vista atual, trataremos, é claro, de sua teoria da inflação. Além de ser sua obra mais conhecida, A inflação brasileira permanece como leitura obrigatória em qualquer curso sobre o tema.

Ele inicia o primeiro capítulo com a equação de trocas, reconhecendo sua contribuição ao estudo dos fenômenos monetários. Mas, desde logo, critica a interpretação específica dos monetaristas, para quem os preços dependem da oferta monetária. Ao contrário: partindo da mesma equação, contempla a hipótese de uma variação autônoma dos preços.

Numa economia monopolista, o ajuste ao desequilíbrio macroeconômico ex- 
presso na equação de trocas deveria ser feito por meio de uma queda na renda agregada. Mas isso não ocorre no caso brasileiro. A economia, em vez de entrar em depressão, engendra outra saída: a emissão. Esta, no entanto, ao contrário do que os monetaristas pensavam, "não é o ponto de partida da inflação, mas seu ponto de chegada" ${ }^{14}$.

Mas não bastava indicar que a emissão era a forma de repor o equilíbrio. Era necessário mostrar o mecanismo como isso se dava, ou seja, como "a alta de preços induz à emissão" 15 .

A elevação autônoma dos preços decorre, historicamente, da atuação de empresas com elevado poder de monopólio e que dominam a estrutura de comercialização dos produtos agrícolas. Como esses bens possuem baixa elasticidade-preço de demanda, uma elevação de preços, por meio do efeito-renda, provoca uma queda nas vendas e uma retenção de estoques nas empresas em que predomina a produção de bens com alta elasticidade-renda da demanda, alterando assim a relação entre o disponível e o realizável no balanço dessas empresas. O nível de liquidez anterior será alcançado por meio de empréstimos junto ao sistema bancário, que não tem por que se retrair perante esse tipo de cliente, dotado de elevado índice de solvabilidade. Este movimento, em termos agregados, "afeta negativamente o equilíbrio de caixa do sistema bancário" 16 que, por isso, apresentará problemas de liquidez. O desequilíbrio rebate, finalmente, no Banco do Brasil. "Para socorrer o Banco do Brasil, o governo emite." Com a emissão "o mercado reabsorve os excedentes temporariamente retidos" e o governo recebe um prêmio por seu comportamento heterodoxo, na forma de recursos oriundos de tributos adicionais, de acréscimos de depósitos compulsórios e do próprio valor da emissão.

Embora o governo também se beneficie da inflação, esta não começa no orçamento da União - como diz a tese monetarista - e sim no interior da economia, o que aproxima Rangel dos estruturalistas. Por outro lado, ao influenciar a "taxa de imobilização" do sistema, a inflação cumpre o papel de instrumento de defesa contra a tendência à depressão, a qual resulta, em última instância, de uma industrialização realizada sem prévia reforma agrária e, por isso, feita para atender uma demanda preexistente, localizada nas classes de rendas mais altas; uma industrialização, portanto, que acompanhou a concentração de renda determinada pela velha estrutura agrária. Nessas condições, o combate à inflação não deve ser feito com base no receituário ortodoxo, que levaria a uma crise e, muito provavelmente, a mais inflação.

A obra ultrapassa o momento histórico em que foi escrita. É, de fato, uma teoria, não só pela forma rigorosa de sua formulação, como também por seu elevado grau de universalidade. Apresenta uma dimensão dinâmica pouco comum nas teorias sobre a inflação. Desde sua primeira formulação, ela apareceu diretamente

\footnotetext{
14 “A inflação brasileira”, Obras reunidas, v. I, p. 551.

15 Idem.

${ }^{16}$ Idem.
} 
integrada com o processo de valorização do capital e com a forma cíclica que ele assume historicamente. A integração de aspectos microeconômicos é feita de maneira rigorosa e historicamente correta, observando a estrutura oligopólica da economia brasileira.

$\mathrm{Na}$ segunda metade da década de 1980, em outro contexto, Rangel comentou a teoria da inflação inercial, muito influente a partir do Plano Cruzado. As palavras do autor não deixam dúvidas sobre sua opinião: "A hipótese de que houvesse, no processo inflacionário, uma componente inercial não podia ser descartada a priori. Entretanto, a hipótese de que uma parcela dominante da inflação, ou com maior razão toda ela, fosse atribuível a um movimento inercial, esta, sim, podia ser recusada" ${ }^{17}$.

Como a inflação brasileira, para Rangel, fazia parte da síndrome da recessão — isto é, tinha um caráter cíclico, numa relação inversa com a conjuntura -, o destaque dado à inercialidade era visto como um exagero. Ao analisar o processo de estabilização do Plano Cruzado, ele explicitou claramente o seu ponto de vista: "O notório 'choque heterodoxo', ao mobilizar o apoio entusiástico das grandes massas populares, pareceu justificar-se, acenando com a possibilidade de uma moeda estável e de uma transparência que o véu monetário retirava dos fatos econômicos. Nossos inercialistas nem sequer viram que para o seu 'choque' poder ter êxito fazia-se mister essa intervenção das grandes massas populares, segundo o princípio enunciado por Karl Marx: quando as ideias se apossam da consciência das massas, convertem-se em força material. Eles não viram, nem podiam ver isso, porque se a relativa estabilização da moeda dependia disso, isto é, de que o desejo de estabilização se convertesse numa força material, isso queria dizer que a inercialidade era um mito" ${ }^{18}$.

\section{O ESQUECIMENTO DE RANGEL}

Chegou a hora de esboçar um balanço sucinto sobre aspectos centrais da obra de Rangel, vista a partir de hoje, e de sua influência. Começamos por ressaltar algo estranho, que demanda uma explicação: o esquecimento da tese da dualidade básica pela nossa historiografia. Outras contribuições de Rangel logo foram incorporadas ao debate brasileiro, e nele permaneceram com destaque. Mas a tese central de sua obra, não. Apesar de ter sido bem recebida quando apresentada pela primeira vez ${ }^{19}$, ela não esteve presente nas acesas discussões travadas pela esquerda na década de 1960 em torno da natureza da revolução brasileira, nem influenciou

\footnotetext{
17 “Economia brasileira contemporânea”, Obras reunidas, v II, p. 495.

18 Idem.

19 Ver a apresentação de Guerreiro Ramos para a primeira edição de Dualidade básica da economia brasileira. Rio de Janeiro, ISEB, 1959.
} 
significativamente os estudos acadêmicos, que se multiplicaram depois, sobre a sociedade colonial e escravista.

O debate sobre a história colonial e sobre as relações entre a economia brasileira e o capitalismo mundial ganhou fôlego nas décadas de 1950 e 1960, no âmbito do antigo Partido Comunista Brasileiro (PCB), e girou em torno da etapa da revolução brasileira. A posição oficial identificava a predominância do feudalismo no campo, cujo peso econômico e demográfico era então determinante na sociedade brasileira. Isso impunha à revolução um caráter democrático-burguês, antifeudal e anti-imperialista.

Depois do golpe militar de 1964 cresceram as críticas a essa visão. Ganharam destaque as posições de Caio Prado Jr., que negava o caráter feudal das relações de produção vigentes no campo: o "sentido da colonização", determinado pelas relações externas entre Colônia e Metrópole, sempre fora marcadamente capitalista.

Sob o impacto de uma grande derrota política ainda recente e com a cobertura dessa revisão doutrinária, parte da esquerda redefiniu a etapa da revolução brasileira como anticapitalista e anti-imperialista, em oposição aberta às teses oficiais do PCB. Nessas novas visões, a ênfase recaiu sobre os vínculos que uniam, em um só bloco dominante, o latifúndio, a burguesia nacional e os interesses estrangeiros. O movimento revolucionário deveria levar outro bloco de classes ao poder, centrado em operários e camponeses, o que lhe conferiria um caráter socialista.

Salta à vista a ausência de referências à tese rangeliana nesse contexto, pois ela era relevante e bem conhecida pelos intelectuais dessa época ${ }^{20}$. Tinha sido amplamente discutida no Instituto Superior de Estudos Brasileiros (ISEB), instituição onde atuava Nelson Werneck Sodré, um dos principais teóricos do PCB. O próprio Rangel militara no PCB até 1947, e sua teoria aparecia em pelo menos três obras publicadas no início da década de 1960: Recursos ociosos, A questão agrária brasileira e A inflação brasileira.

$\mathrm{Na}$ década de 1970 o debate retornou com nova roupagem, arejado por uma versão local do "marxismo ocidental" de corte mais acadêmico' ${ }^{21}$. A historiografia brasileira produziu trabalhos relevantes sobre o período colonial. Ganhou destaque a tese de Fernando Novais, que, desenvolvendo a posição de Caio Prado Jr., apresentou a dinâmica da economia colonial no contexto da acumulação primitiva de capital, privilegiando as relações com a Metrópole para explicar a Colônia. Ela foi contestada por uma nova abordagem proposta por partidários da posição oficial

\footnotetext{
${ }^{20}$ A inexistência de referências a Rangel nesse debate foi registrada por Mamigonian (1998).

${ }^{21}$ Não faremos uma resenha do debate que, pela importância teórica, histórica e política, passa por constantes avaliações e desenvolvimentos. Além dos trabalhos já clássicos, que definiram em grandes linhas a problemática - trabalhos de Nelson Werneck Sodré, Alberto Passos Guimarães, Caio Prado Jr., Fernando Novais, Ciro Cardoso, Jacob Gorender, para citar alguns -, o debate foi visitado por seminários e teses acadêmicas e parece longe de ter sido esgotado pelos estudiosos brasileiros. Para exemplificar o esforço acadêmico lembramos os trabalhos de Lapa (1980), Sampaio Jr. (1999), Vieira (2004).
} 
do PCB, que privilegiava as determinações endógenas à Colônia. Dois autores se destacaram nessa reflexão: Ciro Cardoso e Jacob Gorender.

Ora, as grandes questões presentes nesse debate tinham sido competentemente trabalhadas por Ignácio Rangel. Sua tese não só enfatizava a simultaneidade e a alternância das relações externas e internas, como apontava, como vimos, para um movimento articulado com os movimentos da economia mundial, marcadamente os ciclos de Kondratieff. As questões relativas ao desenvolvimento do mercado interno na economia colonial, que aparecem como um ponto de clivagem, haviam sido tratadas por Rangel com notável rigor analítico. O próprio conceito de dualidade trazia em si a ideia de um modo de produção específico, enraizado na história do Brasil.

Por que, então, a posição de Rangel não mereceu maior atenção nesse debate historiográfico? Talvez, pelo uso heterodoxo que ele fazia das teorias econômicas, da economia política clássica e marxista, e do materialismo histórico. Além disso, a nosso ver, a rejeição à teoria da dualidade, proporcional à sua engenhosidade, deve-se em grande medida ao fato de que dela se extraía uma teoria do avanço não revolucionário da sociedade brasileira, o que não se harmonizava com o ambiente intelectual e político das esquerdas brasileiras da época. "A ideia da dualidade não se encaixava bem nem na posição ortodoxa [do antigo PCB] nem na revisão teórica que tomou corpo a partir de A revolução brasileira, de Caio Prado Jr." ${ }^{22}$.

Se essa interpretação estiver correta, é curioso constatar que, guardadas as devidas proporções, o isolamento de Rangel, no Brasil, e de Kondratieff, na União Soviética, teve um fundo comum, com décadas de distância: suas teorias não se ajustavam aos desejos revolucionários dos comunistas mais ortodoxos.

Os marxistas brasileiros permaneceram fiéis ao paradigma oficial. Ideias como revolução, luta de classes e socialismo eram manejadas como palavras de ordem, não como categorias analíticas, ao contrário do que fazia Rangel. Na teoria da dualidade, as contradições entre relações de produção e desenvolvimento das forças produtivas, aspecto central dos discursos revolucionários, aparecem como um movimento quase natural de superação: as forças produtivas se desenvolvem sem colidir frontalmente com as relações de produção. Essa plasticidade permitia uma evolução impulsionada por uma luta de classes travada entre as elites, sem participação relevante dos trabalhadores. Nada mais herético para um debate travado no campo socialista!

\section{RANGEL E AS PRIVATIZAÇÕES}

Ocupando posições relevantes no cenário político e intelectual brasileiro, a partir do ISEB e do BNDE, Rangel teve presença ativa no período que antecedeu o golpe militar de 1964, mas, como vimos, sua heterodoxia impediu que, em vida,

22 Cf. Castro (2005). 
exercesse influência mais ampla. Depois de sua morte, a ideia pioneira da privatização dos serviços públicos foi apropriada de maneira enviesada, no contexto de uma política econômica que ele sempre detestou.

A maneira como foram feitas as privatizações brasileiras e as transformações estruturais da nossa economia nos últimos vinte anos conduziram a um quadro adverso aos efeitos desenvolvimentistas que Rangel pretendia obter. A grande questão não envolve a privatização em si ou a solução jurídica, que ele encontrou, para garantir o financiamento da infraestrutura. É da própria dinâmica de crescimento que se trata: Rangel estava preocupado em enfrentar as travas financeiras para o que entendia ser a nova etapa de desenvolvimento das forças produtivas a partir da década de 1980, caracterizada pelo crescimento puxado pela expansão da infraestrutura e pela mobilização da produção interna de bens de capital.

$\mathrm{Na}$ inserção produtiva e financeira da economia brasileira das últimas décadas, os efeitos dinâmicos do investimento em infraestrutura se projetaram em direções diferentes das que ele desejava. Muitas questões se acumulam, sem solução. Como induzir investimentos nas empresas privatizadas, se a principal motivação das aquisições de estatais não é a operação em si, nem, muito menos, a sua expansão, mas sim o ganho patrimonial? Como planejar os investimentos, financiá-los e dirigir a demanda derivada para o aparelho produtivo doméstico? Como atrair capitais privados para financiar atividades remuneradas por tarifas? Como combinar parcerias público-privadas (PPPs) com investimentos privados em infraestrutura? Como recuperar as finanças com lastro no Estado, quando o movimento geral da política econômica aposta em modelos mercantis para organizar o setor de infraestrutura? A remuneração dos investimentos será baseada em preços ou em tarifas?

\section{A QUARTA DUALIDADE}

Por fim, que dizer da quarta dualidade, hoje? Rangel estudou diferentes aspectos da economia brasileira durante a vigência da terceira dualidade, que corresponde, esquematicamente, ao período entre 1930 e 1973. O conjunto de sua obra busca explicar como pôde ter ocorrido um vigoroso desenvolvimento capitalista sem reforma agrária. Para isso, construiu um modelo criativo e eficaz, mas parece ter confiado demais em sua capacidade prospectiva. Segundo ele, a crise que começou na segunda metade da década de 1970 desembocaria nessa nova dualidade, com o capitalismo agrário no polo interno e o capitalismo financeiro, conduzido pelo Estado, no polo externo. As leis da dualidade, mais uma vez, modulariam as mudanças que vinham de fora para dentro, sem que a possibilidade de fracasso fosse aventada.

Passados cerca de trinta anos, podemos constatar que a teoria não previu corretamente o que estava por vir. Mais uma vez sob o decisivo impacto do sistema internacional - aí incluídos, com destaque, a desestruturação da União Soviética, o reforço da hegemonia dos Estados Unidos e o incremento da globalização -, a economia brasileira caminhou em outras direções. 
(a) A dialética da capacidade ociosa ficou ameaçada pelas transformações estruturais associadas à internacionalização dos últimos vinte anos. As transformações da indústria brasileira, que muitos identificam como desindustrialização ${ }^{23}$, atuam no sentido de suprimir essa capacidade ociosa, ou poupança potencial. A globalização das cadeias produtivas, com o vazamento da demanda interna para o exterior, diminui o efeito multiplicador dos investimentos nos setores estrangulados. A dinâmica globalizada da nossa economia pode ter desconectado a acumulação industrial, de um lado, e os ciclos endógenos brasileiros, de outro.

(b) Na visão de Rangel, como vimos, o capital financeiro nacional, constituído com ativos pertencentes a empresas nacionais ou estrangeiras aqui instaladas, desempenharia um papel relevante na superação da crise, com o financiamento dos setores de utilidade pública que deveriam ser privatizados. Contudo, a internacionalização do sistema financeiro e a integração financeira desregulamentada também extinguiram a possibilidade de organização estatal de um mercado de capitais e das finanças, em moeda nacional, para financiar o nosso desenvolvimento.

(c) A nova inserção global da economia brasileira induziu parte significativa da burguesia industrial a se transformar em rentista ou comerciante, enfraquecendo sua vontade e sua capacidade de constituir o núcleo da quarta dualidade. $\mathrm{O}$ mesmo ocorre com uma burguesia agrária inserida em uma cadeia produtiva completamente internacionalizada, desde os insumos até os esquemas de comercialização.

Em síntese: a teoria da dualidade tem grande poder explicativo quando aplicada à história brasileira passada, especialmente a dos séculos XIX e XX, mas a ideia do estabelecimento de uma quarta dualidade revelou-se problemática, retirando da teoria as suas possibilidades prospectivas. Reconhecer essa limitação de uma tese enunciada há mais de cinquenta anos não deixa de ser uma forma de homenagear seu autor.

\section{REFERÊNCIAS BIBLIOGRÁFICAS}

CASTRO, M. H. M (2005) “Nosso mestre Ignácio Rangel”(2005). In Rangel (2005).

KONDRATIEFF, Nicolai (1984) The Long Wave Cycle. St. Moritz: International Moneyline.

LAPA, Jose R. Amaral, org. (1980) Modos de Produção e Realidade Brasileira, São Paulo: Vozes.

MAMIGONIAN, A. (1998) "Notas sobre as raízes e originalidade do pensamento de Ignácio Rangel", In MAMIGONIAN, A. e REGO, J. M., orgs. O Pensamento de Ignácio Rangel. São Paulo, Editora 34 .

RANGEL, Ignácio M. (1957) A Dualidade Básica da Economia Brasileira, Rio de Janeiro: ISEB, Instituto Superior de Estudos Brasileiros. In Rangel (2005)

RANGEL, Ignácio M. (1962) "A dinâmica da dualidade brasileira”, Revista Brasileira de Ciências Sociais da Faculdade de Ciências Econômicas da Universidade de Minas Gerais, volume II, n. 2. In Rangel (2005).

${ }^{23}$ Cf. Cano (2013). 
RANGEL, Ignácio M. (1960) Recursos Ociosos e Política Econômica (coletânea de ensaios publicados em 1960), São Paulo: Editora Hucitec. In Rangel (2005)

RANGEL, Ignácio M. (1978a) A Inflação Brasileira, Rio de Janeiro, Tempo Brasileiro, $3^{\text {a }}$ edição com posfácio e subsequentes: São Paulo, Editora Brasiliense. In Rangel (2005)

RANGEL, Ignácio M. (1978b) "Dualidade e 'escravismo colonial”",. Encontros com a Civilização Brasileira, $\mathrm{n}^{\circ}$ 3. In Rangel (2005)

RANGEL, Ignácio M. (1981) “A História da Dualidade Brasileira”, Revista de Economia Política, 1(4): 5-34. In Rangel (2005)

RANGEL, Ignácio M. (1987) Economia Brasileira Contemporânea, São Paulo: Editora Bienal. In Rangel (2005)

RANGEL, Ignácio M. (1990) “Quarta dualidade”, inédito.

RANGEL, Ignácio M. (1992) “Entrevista com o professor Ignácio de Mourão Rangel”. GEOSUL $12 / 13$.

RANGEL, Ignácio M. (2005) Obras Reunidas (dois volumes), organizador: César Benjamin, Rio de Janeiro: Contraponto.

SAMPAIO Jr., Plinio de Arruda (1999) "Para retomar o debate brasileiro". In José Fiori, org. Estados e Moedas no Desenvolvimento das Nações”. São Paulo: Vozes.

SCHUMPETER, Joseph A. (1968) "El análisis del cambio económico", Ensayos. Barcelona, Oikos-Tau. VIEIRA, Carlos A. Cordovano (2004) "Interpretações da colônia”. Unicamp — Tese. 